\title{
A FUZZY MULTIPLE CRITERIA COMPARISON OF TECHNOLOGY VALUATION METHODS FOR THE NEW MATERIALS DEVELOPMENT
}

\author{
An-Chin CHENG \\ Chaoyng University of Technology, \\ Jifeng E. Rd. 168, 41349 Wufeng District Taichung, Taiwan
}

Received 25 November 2011; accepted 03 March 2012

\begin{abstract}
New materials have been recognized as key drivers for corporate profitability and growth in today's fast changing environment. To evaluate the development and gain useful appraising information of new materials thus becomes a critical issue. However, little has been done in discussing the selection of technology valuation methods for the development of new materials. Accordingly, this study adopted the fuzzy AHP method to obtain the opinions of professionals on this issue. These efforts resulted in seven evaluation criteria with one, the "data validity" being given the highest weight, followed by "method adaptability" and "technology development evaluability". It was concluded that the real option approach and income method are the two most applicable technology valuation methods for evaluating new materials development. In addition, the application of the fuzzy AHP method provided a relevant avenue for corporation policy makers and researchers to evaluate the technology valuation methods for new materials.
\end{abstract}

Keywords: new materials development, fuzzy, technology valuation, fuzzy AHP.

Reference to this paper should be made as follows: Cheng, A.-C. 2013. A fuzzy multiple criteria comparison of technology valuation methods for the new materials development, Technological and Economic Development of Economy 19(3): 397-408.

JEL Classification: C52, D70, D81, G11, G12.

\section{Introduction}

New materials have been recognized as key drivers for corporate profitability and growth in today's fast changing environment. Usually these come about through the replacement of natural materials by synthetic ones that are cheaper or better. The replacement of silk by nylon and the substitution of cotton by a whole host of synthetic fibers are such examples

Corresponding E-mail:

cheng.ac@gmail.com 
(Martino 1993). In addition to this, nanotechnology is emerging as an important technological change in new materials. Many industries such as semiconductors and chemicals are already creating products with enhanced performance based on new materials with nanosized features. According to the estimation by the National Science Foundation (USA), the nanotechnology market will experience steep annual growth, capable of bringing in more than US\$ 1 trillion after the 2010 (Business Communications Co. Inc. 2003; President's Council of Advisors on Science and Technology 2005).

However, there are many uncertainties and risks in new materials development. Hence, it is very significant to maintain company niches in the market and develop unique abilities through the management of intellectual property rights. Intellectual property rights include brand valuation, trademark rights, patent rights and so on; but in the field of new materials which is technology-intensive, patent rights play a major and crucial role (Cheng et al. 2008; Wartburg, Teichert 2008). Enterprises can obtain greater income by licensing their patents to other IP (intellectual property) users. On the other hand, enterprises can also purchase patents from IP providers to reduce their R\&D risk.

Consequently, the selection of an appropriate technology valuation method to gain useful valuation information about the new material becomes more and more important. However, little has been done in assessing the selection of technology valuation methods on this topic. Accordingly, the main purposes of this study are the identification of the critical evaluation criteria and the evaluation of the technology valuation methods for these new materials.

Over the past two decades, there has been a growth in the number of multiple criteria decision-making methods for assisting decision-making (Peldschus 2009; Zavadskas, Turskis, 2011). These allow decision-makers to evaluate various alternatives for achieving their goal. Among these, the fuzzy analytic hierarchy process (FAHP) is one of the most popular (Zhau, Goving 1991; Ghotb, Warren 1995; Teng, Tzeng 1996; Cheng et al. 2008; Aydın, Arslan 2009; Zhang, Liu 2010; Han, Liu 2011; Kaya, Kahraman 2011; Parsaeia et al. 2012; Zolfani et al. 2012; Fouladgar et al. 2012). People often use knowledge that is imprecise rather than precise. The fuzzy set theory can resemble human reasoning in the use of approximate information and uncertainty to generate decisions. It was specifically designed to mathematically represent uncertainty and vagueness, and provide formalized tools for dealing with the imprecision intrinsic to many problems (Zadeh 1965; Williams 2003; Kahraman et al. 2004; Han, Liu 2011). Consequently, in order to make this study more sensible and gain a more representative description of the decision-making process, this paper would apply the fuzzy AHP to evaluate the technology valuation methods for the new materials field.

\section{Review and classification of technology valuation method}

Technology valuation is used to estimate the value of an activity to review its technological, commercial and marketability factors with intangible technology itself (Smith, Parr 1994). There are three well-known approaches to the valuation of technology. They are the cost-based approach, market reference, and income method (Mard 2000a, b; Pavri 1999). In addition to these three approaches, the real option approach has become the latest (Boer 2004). 
The cost-based approach is based on the economic principle of substitution, that postulates that a prudent buyer would pay no more and a willing seller could command no more for a technology than the cost to create an intellectual asset of equal desirability and utility. Specifically, there are two radical types in the cost-based approach, namely reproduction cost and replacement cost. Reproduction cost contemplates the construction of an exact replica of the subject intellectual property. Replacement cost considers the cost to recreate the functionality or utility of the subject technology, but in a form or appearance that may be different from the subject technology. Both types take into account depreciation and obsolescence (Park, Y., Park, G. 2004). Furthermore, the cost-based approach has the advantage of simplicity and ease of application. However, the cost-based approach has its limitations. It is unable to capture the economic benefits and the potential of the technology due to difficulties in obtaining the underlying data and identifying depreciation factors (Mard 2000a, b; Pavri 1999; Boer 2004).

The market reference method is based on the knowledge that there is an active market in similar technologies, and the value of this intellectual property asset is determined by comparison with sales or licenses of similar technologies or intellectual property. It is a simple and logical method. However, the prerequisite for the market reference method is the existence of an active public market and transaction data of comparable properties. It is limited since there is rarely an active market in which public information, price and comparability is readily available (Boer 2004; Park, Y., Park, G. 2004).

The income method is based on the discounted cash flow (DCF) theory. It is measured by the net present value (NPV) of associated economic benefits over the lifetime of the technology. The value is determined by the income-producing capability of the subject technology. To use this method effectively, income statements must be projected for the life of the technology and an appropriate discount rate applied. Therefore, it also takes the chance of introducing errors due to its subjective estimation of major parameters (Smith, Parr 1994; Boer 2004).

The real option approach is borrowed from the widely used method for valuing financial options (Faulkner 1996). This reflects the unexpected market for decision making. With respect to variability, contingency and flexibility, the option approach is quite useful. This real option is comparable to a financial option in that it gives a firm a right, but not the obligation, to do something in the future. However, the real option differs from a financial option in its practical application. In particular, these real options are subject to uncertainty, i.e. the value of the options changes as time evolves and new information about the investment project comes in (Wu, Yen 2007; Wörner, Grupp 2003; Jerak, Wagner 2006; Ernst et al. 2010; Verdu et al. 2012). Three levels of real option thinking can be distinguished (Faulkner 1996; Wu, Yen 2007; Wörner, Grupp 2003; Dissel et al. 2005). The starting level is to realize that some investments can be understood as options, in that what is being paid for is the "right to play" and that there is no guaranteed pay-off. The second level focuses on quantifying the value of the flexibility in projects by using decision trees and estimated probabilities (Faulkner 1996). These approaches encourage the exploitation of uncertainty rather than the fear of it. The third level of real option thinking refers to the mathematical modeling techniques that have proved successful in the financial markets. It brings in the ideas of replicating portfolios and of arbitrage pricing, i.e. what should the price of this option be so that no-one can make 
"excessive" guaranteed profits (Dissel et al. 2005). Accordingly, nowadays the real option approach is gaining growing attention due to its flexibility.

To sum up, Table 1 presents the definitions and comparisons of the technology valuation methods described (Park, Y., Park, G. 2004; Jang, Ryu 2008).

Table 1. Definitions and comparisons of technology valuation methods

\begin{tabular}{lllll}
\hline Method & Cost-based approach & Market reference & Income method & $\begin{array}{l}\text { Real option } \\
\text { approach }\end{array}$ \\
\hline Definition & $\begin{array}{l}\text { Valuation based } \\
\text { on cost required to } \\
\text { reproduce or replace } \\
\text { technology }\end{array}$ & $\begin{array}{l}\text { Valuation based } \\
\text { on the price } \\
\text { of comparable } \\
\text { technologies in } \\
\text { the market }\end{array}$ & $\begin{array}{l}\text { Valuation based on } \\
\text { the present worth } \\
\text { of future income } \\
\text { flow }\end{array}$ & $\begin{array}{l}\text { Valuation } \\
\text { adjusted for } \\
\text { factors of risk } \\
\text { and uncertainty }\end{array}$ \\
\hline Advantages & $\begin{array}{l}\text { Easy to calculate } \\
\text { and use }\end{array}$ & $\begin{array}{l}\text { Possible to } \\
\text { calculate the most } \\
\text { rational value if } \\
\text { market data is } \\
\text { available }\end{array}$ & $\begin{array}{l}\text { Possible to } \\
\text { capture present } \\
\text { worth based on } \\
\text { profit-generating } \\
\text { capability }\end{array}$ & $\begin{array}{l}\text { Takes } \\
\text { uncertainty and } \\
\text { risk into account, } \\
\text { rendering a more } \\
\text { flexible valuation }\end{array}$ \\
\hline
\end{tabular}

Source: The authors' study based on Park, Y., Park, G. 2004.

\section{The fuzzy analytic hierarchy process}

There has been a growth in the number of multiple criteria decision-making methods for assisting decision-making over the past two decades. These allow decision-makers to evaluate various alternatives for achieving their goal. Among these, the fuzzy analytic hierarchy process (FAHP) is one of the most popular (Kahraman et al. 2004; Ghotb, Warren 1995; Teng, Tzeng 1996; Zhau, Goving 1991; Zolfani et al. 2012; Fouladgar et al. 2012). People often use knowledge that is imprecise rather than precise. The fuzzy set theory could resemble human reasoning in use of approximate information and uncertainty to generate decisions. In fuzzy set terminology, the ratio supplied by the decision maker is a fuzzy number described by a membership function. The membership function describes the degree to which elements in the judgment interval belong to the preference set (Zhau, Goving 1991). Fuzzy AHP consists of deriving the local priorities from these fuzzy preference ratios, which are subsequently aggregated to form the whole priorities. Because the preferences in AHP are essentially judgments based on the perception of human beings (especially for intangibles), the fuzzy approach allows a more representative description of the decision making process (Ghotb, Warren 1995).

There are several possible ways to represent fuzzy numbers. It is common to use a triangular fuzzy number, which is relatively easy to model and works well with most applications. The membership function $\mu_{A}(x)$ of a triangular fuzzy number is shown in Eq. (1) and Fig. 1:

$$
\mu_{A}(x)=\left\{\begin{array}{l}
(x-L) /(M-L), L \leqq x \leqq M, \\
(U-x) /(U-M), M \leqq x \leqq U, \\
0, \text { otherwise, }
\end{array}\right.
$$

where $L \leqq M \leqq U, L$ and $U$ stand for lower and upper value of the support of $A$, and $\mu_{A}(x) \rightarrow[0,1]$. 


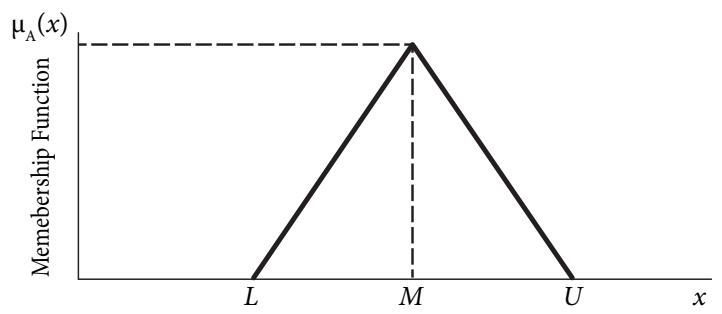

Fig. 1. Membership function of the triangular fuzzy number

In this study, we adopt the triangular fuzzy number to represent the measurement of the experts' view toward the preference of assessment by forming the pairwise comparison matrix. The matrix is called the fuzzy positive reciprocal matrix, $\tilde{M}=\left[\tilde{m}_{i j}\right]_{n^{*} n}$. Here $\tilde{M}$ represents the fuzzy positive reciprocal matrix and $\tilde{m}_{i j}$ is the fuzzy number of the experts' preference.

The whole of the fuzzy AHP process used in our study is as follows:

Step 1. Creating the hierarchy layers: Based on the characteristics decomposed by each attribute, the hierarchical structure of our model is constructed as shown in Fig. 2. The top level is the main objective, which is to evaluate which technology valuation methods would be best in appraising the development of the new materials. The second level is the key evaluation criteria for assessing the objective. Here, there are seven key criteria, identified by interviewing the experts. They are: data availability, data validity, technology development evaluability, technology applicability, method adaptability, ease of operation, and implementation cost. Finally, four technology valuation method candidates are placed at the bottom of the model. These include cost-based approach, market reference, income method, and real option approach.

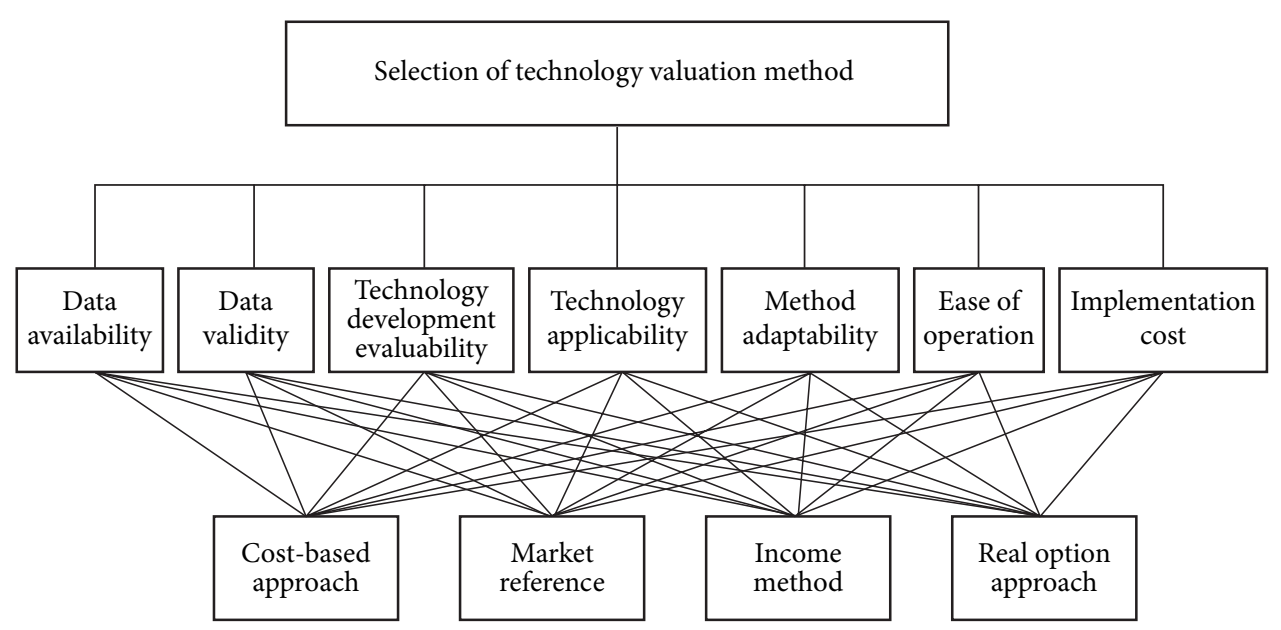

Fig. 2. The fuzzy AHP model 
Step 2. Group integration: After the polling process, we convert the experts' opinion into fuzzy numbers by the following equations:

$$
\tilde{M}_{i j}=(1 / N) \otimes\left(\tilde{m}_{i j}^{1} \otimes \tilde{m}_{i j}^{2} \otimes \cdots \otimes \tilde{m}_{i j}^{N}\right)
$$

where $\tilde{M}_{i j}$ is the integrated triangle fuzzy number, $\tilde{m}_{i j}^{k}$ is the $i$-th to the $j$-th factor pair comparison by expert $k$, and $N$ is the total number of experts.

Step 3. Building the fuzzy positive reciprocal matrix: From the step 2, we obtain the final calculated fuzzy numbers for each layer.

Step 4. Calculating the factors' fuzzy weights: A modified formula for the fuzzy weights is shown below.

$$
\tilde{Z}_{i}=\left(\tilde{a}_{i 1} \otimes \tilde{a}_{i 2} \otimes \cdots \tilde{a}_{i n}\right)^{1 / n}, \nabla i
$$

where: $\tilde{a}_{i j}$ - the $i$-th to the $j$-th triangular fuzzy number of the fuzzy positive reciprocal matrix; $n$ - the factor numbers in each layer; $\tilde{Z}$ - the geometric mean of the triangle fuzzy number

$$
\tilde{W}_{i}=Z_{i} \otimes\left(\tilde{Z}_{1} \oplus \tilde{Z}_{2} \cdots \oplus \tilde{Z}_{n}\right)^{-1}
$$

$\tilde{W}_{i}$ : the fuzzy weight of the $i$-th factor.

Step 5. Hierarchy layer sequencing: Calculate the fuzzy weight values for the alternatives as follows:

$$
\tilde{T}_{i}=\sum_{j=1}^{n} \tilde{W}_{j} \bullet \tilde{E}_{i j},
$$

where $\tilde{T}_{i}$ is the alternative policy fuzzy weights, $\tilde{W}_{j}$ is the fuzzy weight for the key factor, and $\tilde{E}_{i j}$ is the score for the selective alternatives $E_{i}$ to the key factor $E_{j}$.

Step 6. De-fuzzification: It is necessary to transform a fuzzy number into a non-fuzzy number in order to rank the projects. In many research projects, the procedure for de-fuzzification is to locate the Best Non-fuzzy Performance (BNP) value. Methods of such de-fuzzified fuzzy ranking include the mean of maximal (MON), centre of area (COA), and a-Cut (Teng, Tzeng 1996; Zhau, Goving 1991). To utilize the COA method to determine the BNP is simple and practical. The BNP value of the fuzzy number can be calculated as follows:

$$
\mathrm{BPN}_{j}=\left[\left(U_{i}-L_{i}\right)+\left(M_{i}-L_{i}\right)\right] / 3+L_{i}, \nabla i .
$$

Step 7. Ranking the projects: Finally we are able normalize the $\mathrm{BPN}_{j}$. The formula is $P_{i}=\mathrm{BPN}_{j} / \Sigma \mathrm{BPN}_{j}$. The projects can be ranked according to the $P_{i}$ value.

\section{Research design}

\subsection{Data collection and analysis}

The participants included industry practitioners, research analysts and academic researchers experienced in the development of the new materials industries. The research analysts are in the renowned research institutes such as Industrial Technology Research Institute, Metal 
Industries Research and Development Center, and the academic researchers are in the prestigious universities including the National Taiwan University, National Chiao Tung University and National Cheng Kung University.

The survey was conducted in two stages; first, eight experts were interviewed in order to formulate the hierarchy with the seven evaluation criteria and the alternative technology valuation methods. Then questionnaires were sent to the targeted experts, and 18 responses were received. A script was included to ensure consistency and eliminate any bias that could be caused by the phrasing of the questions. In this study, we followed the fuzzy AHP formulas which were mentioned previously, and finally produced a set of global weights or priorities for the alternatives.

\subsection{Survey design}

The survey was conducted to determine how the experts perceived the relative importance of the evaluation criteria and the technology valuation methods (Chen, Huang 2004). A questionnaire was developed based on the fuzzy analytic hierarchy. The seven evaluation criteria are: data availability, data validity, technology development evaluability, technology applicability, method adaptability, ease of operation, and implementation cost. Data availability refers to the extent of availability of data used for the specific technology valuation method. Data Validity reflects the degree of validity of the required data for the specific technology valuation method. Technology development evaluability describes the extent to which the technology valuation method is able to evaluate the development of the new technology. Technology applicability refers to the level of capability to which the technology valuation method appraises the application of the new technology. Method adaptability describes how match between experts' opinions and technology valuation methods (Poh et al. 2001). Ease of operation reflects the degree of difficulty in using the technology valuation method. Implementation cost describes the amount of money used for implementation of the technology valuation method. In addition, four technology valuation methods, the cost-based approach, market reference, income method and real option approach, were included in the fuzzy analytic hierarchy as the decision alternatives.

Each question in the questionnaire consists of a pairwise comparison of two elements at the same level of the hierarchy. Therefore, the seven criteria in the analytic hierarchy result in a total of 21 questions. For each question, the respondents were asked to indicate the relative importance of the two criteria with respect to the objective. Next, the respondents were asked to pairwise compare the technology valuation methods with respect to each criterion. There are four technology valuation methods for the seven criteria, resulting in a total of 42 questions.

\section{Results and discussion}

\subsection{Comparison of the evaluation criteria}

In this study, we first examined the relative importance of the criteria with respect to the primary objective, the choice of technology valuation methods. Following fuzzy AHP methodology, priorities of evaluation criteria were performed to obtain the relative importance 
Table 2. Priorities of evaluation criteria with respect to the goal

\begin{tabular}{lccccc}
\hline \multicolumn{1}{c}{ Relative importance } & \multicolumn{3}{c}{ Fuzzy Weight } & Priority & Ranking \\
& (Triangular Fuzzy Numbers) & & \\
\hline Data availability & $\left(\begin{array}{lllll}0.077, & 0.105, & 0.157\end{array}\right)$ & 0.103 & 5 \\
\hline Data validity & $\left(\begin{array}{lllll}0.161, & 0.251, & 0.346\end{array}\right)$ & 0.231 & 1 \\
\hline Technology development evaluability & $\left(\begin{array}{lllll}0.131, & 0.185, & 0.256\end{array}\right)$ & 0.174 & 3 \\
\hline Technology applicability & $(0.101$, & 0.149, & $0.211)$ & 0.140 & 4 \\
\hline Method adaptability & $(0.147$, & 0.211, & $0.315)$ & 0.205 & 2 \\
\hline Ease of operation & $(0.045$, & 0.063, & $0.107)$ & 0.065 & 7 \\
\hline Implementation cost & $(0.057$, & 0.086, & $0.124)$ & 0.081 & 6 \\
\hline
\end{tabular}

of the factors. Table 2 shows priorities of the evaluation criteria for the goal. The normalized weights and the rank for the criteria are given in the last two columns.

According to Table 2, the results indicate that the criterion data validity has the highest weight of 0.231 , followed by the criterion method adaptability which has the weight of 0.205 . This shows that when we carry out new material technology valuations, the most important factor we should be concerned with the validity of the data. Besides how adaptive between the experts' opinions and each technology valuation method is also the key criteria we should consider more.

Technology development evaluability, technology applicability and data availability have weights of $0.174,0.140$, and 0.103 respectively. These indicate that they are perceived comparatively as secondary level factors and are tactically important. Before a new material becomes popular, there are a lot of uncertainties and different variables affecting its development and applications. A good technology valuation method could have the capability to overcome the uncertainties as much as possible. Furthermore, the more research data you can get, the more the evaluation uncertainties can be reduced.

Implementation cost and ease of operation have weights of 0.081 and 0.065 respectively, and are comparatively unimportant. These results indicate that when decision makers choose the technology valuation methods for new materials development, these two are the least significant.

\subsection{Comparison of the technology valuation methods with respect to the criteria}

In this section, we discuss the comparisons performed on the alternative technology valuation methods with respect to each level-two criterion. Table 3 provides a summary of the overall results of the comparative study. The last two columns present the overall weights and ranks given to the five technology valuation methods.

The real option approach had the highest weight of 0.280 , followed by the income method with a weight of 0.264 . From Table 3 we can see that the real option approach attains the highest local weighting in five criteria, while the income method earns the highest local weight in one criterion and the second highest local weights in five criteria. The rest of the new materials technology valuation methods, in decreasing order of importance, are market reference and cost-based approach. 


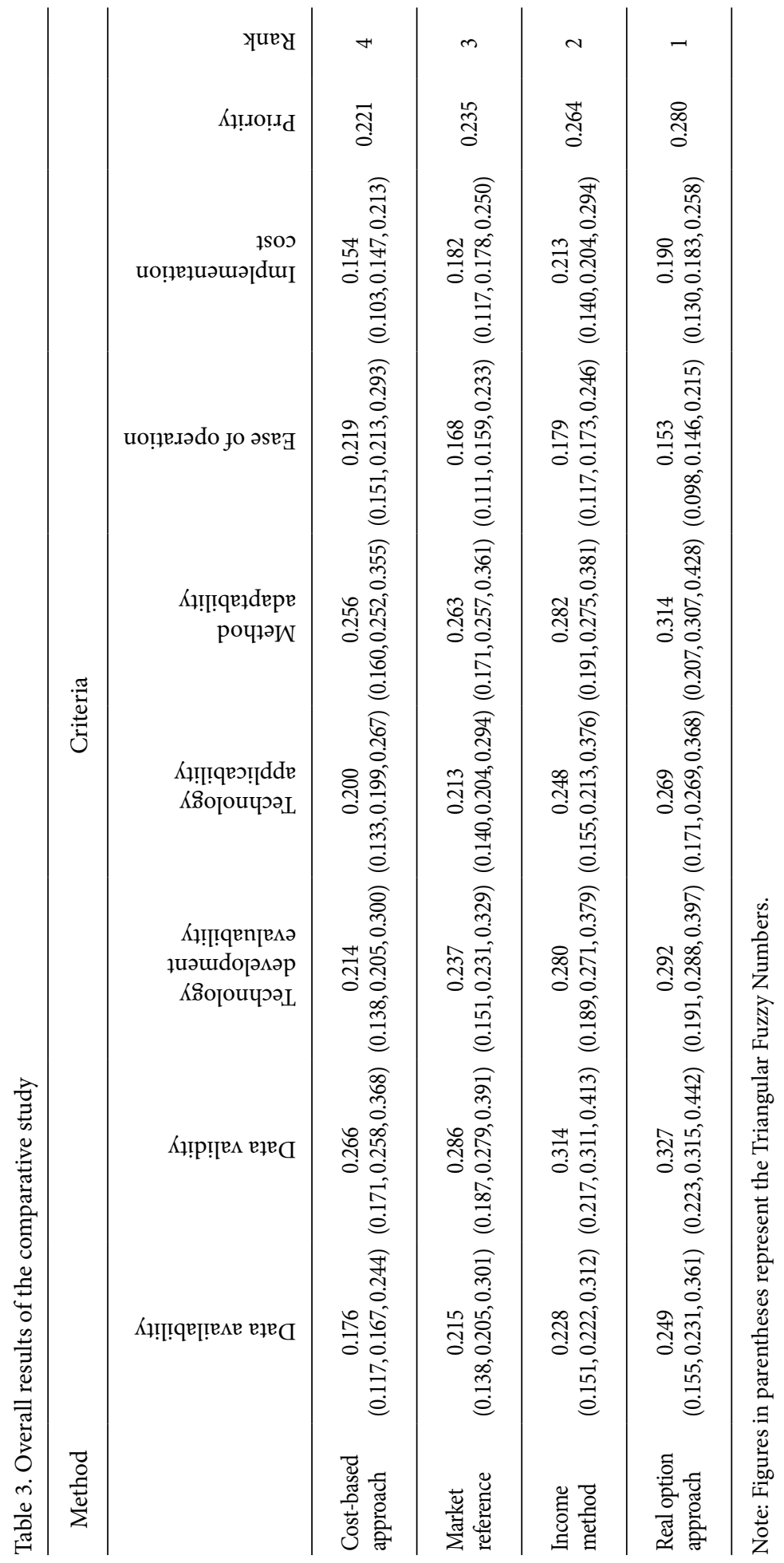


These findings reflect which technology valuation method is deemed most suitable for adopting in the field of new materials. In general, the real option approach is the most favored method for evaluating the development of new materials. However, if the decision maker is more concerned with the ease of operation and implementation costs, the cost-based approach and income method may be more favorable for carrying out the evaluation.

\section{Conclusions}

New materials have been recognized as key drivers for corporate profitability and growth in today's fast changing environment. To evaluate the development and gain useful appraising information of new materials thus becomes a critical issue. Through an appropriate technology valuation method to gain the useful appraising information about the management of intellectual property rights of the new materials becomes more and more significant. The main purpose of this study is to select the most suitable technology valuation method in the field of new materials. Moreover, since little has been done in discussing the selection of technology valuation methods on the topic of new materials, the importance and exigency for this kind of research is amplified.

This study applied the fuzzy AHP method to evaluate and select the technology valuation methods in the field of new materials. People often use knowledge that is imprecise rather than precise. The fuzzy set theory can be used to resemble human reasoning in the use of approximate information and uncertainty to generate decisions. It was specifically designed to mathematically represent uncertainty and vagueness and provide formalized tools for dealing with the imprecision intrinsic to many problems. Consequently, to make this study more balanced, and gain a more representative description of the decision-making process, this paper adopted the fuzzy AHP method to evaluate the technology valuation methods for new materials development.

The two major findings can be defined as follows: Firstly, the results of the evaluation criteria indicate that among the seven evaluation criteria, the criterion data validity has the greatest weight, followed by criteria method adaptability and technology development evaluability in second and third place, respectively. Secondly, based on the subjective judgments made by experts, this comparative study shows that real option approach and the income method are the two most favored technology valuation methods in the field of new materials. The application of the fuzzy AHP method provided a crucial avenue for corporation policy makers and researchers to evaluate the technology valuation methods for new materials.

\section{References}

Aydın, Ö.; Arslan, G. 2009. A new software development for fuzzy multicriteria decision-making, Technological and Economic Development of Economy 15(2): 197-212. http://dx.doi.org/10.3846/1392-8619.2009.15.197-212

Boer, F. P. 2004. Technology valuation solutions. New York: Wiley Publishers.

Business Communications Co. Inc. 2003. Advanced ceramic powders and nano ceramic powders. Massachusetts, USA. 
Chen, C. J.; Huang, C. C. 2004. A multiple criteria evaluation of high-tech industries for the science-based industrial park in Taiwan, Information and Management 41: 839-851. http://dx.doi.org/10.1016/j.im.2003.02.002

Cheng, A. C.; Chen, C. J.; Chen, C. Y. 2008. A fuzzy multiple criteria comparison of technology forecasting methods for predicting the new materials development, Technological Forecasting and Social Change 75(1): 131-141. http://dx.doi.org/10.1016/j.techfore.2006.08.002

Dissel, M.; Farrukh, C.; Probert, D.; Phaal, R. 2005. Evaluating early stage technology valuation methods: what is available and what really matters, IEEE International Engineering Management Conference, September, 2005, Canada, 11-13.

Ernst, H.; Legler, S.; Lichtenthaler, U. 2010. Determinants of patent value: Insights from a simulation analysis, Technological Forecasting and Social Change 77: 1-19. http://dx.doi.org/10.1016/j.techfore.2009.06.009

Faulkner, T. W. 1996. Applying 'options thinking' to R\&D valuation, Research Technology Management 39: $50-56$.

Fouladgar, M. M.; Yazdani-Chamzini, A.; Zavadskas, E. K.; Moini, H. H. 2012. A new hybrid model for evaluating the working strategies: case study of construction company, Technological and Economic Development of Economy 18(1): 164-188. http://dx.doi.org/10.3846/20294913.2012.667270

Ghotb, F.; Warren, L. 1995. A case study comparison of the analytic hierarchy process and a fuzzy decision methodology, The Engineering Economist 40: 233-247. http://dx.doi.org/10.1080/00137919508903151

Han, Z.; Liu, P. 2011. A fuzzy multi-attribute decision-making method under risk with unknown attribute weights, Technological and Economic Development of Economy 17(2): 246-258. http://dx.doi.org/10.3846/20294913.2011.580575

Jang, W. J.; Ryu, J. Y. 2008. Technology valuation model in defense offset trade: Income approach, PICMET: 2521-2534.

Jerak, A.; Wagner, S. 2006. Modeling probabilities of patent oppositions in a Bayesian semi parametric regression framework, Empirical Economics 31:513-533. http://dx.doi.org/10.1007/s00181-005-0047-0

Kahraman, C.; Cebeci, U.; Ruan, D. 2004. Multi-attribute comparison of catering service companies using fuzzy AHP: The case of Turkey, International Journal of Production Economics 87: 171-184. http://dx.doi.org/10.1016/S0925-5273(03)00099-9

Kaya, T.; Kahraman, C. 2011. A fuzzy approach to e-banking website quality assessment based on an integrated AHP-ELECTRE method, Technological and Economic Development of Economy 17(2): 313-334. http://dx.doi.org/10.3846/20294913.2011.583727

Mard, M. 2000a. Financial factors; cost approach to valuing intellectual property, Licensing Journal August: 27-29.

Mard, M. 2000b. Financial factors; cost approach to valuing intellectual property, Licensing Journal September: $27-30$.

Martino, J. P. 1993. Technological forecasting for decision making, $3^{\text {rd }}$ ed. New York: McGraw-Hill.

Park, Y.; Park, G. 2004. A new method for technology valuation in monetary value: procedure and application, Technovation 24(5): 387-394. http://dx.doi.org/10.1016/S0166-4972(02)00099-8

Parsaeia, S.; Keramatia, M. A.; Zorriassatineb, F.; Feylizadehc, M. R. 2012. An order acceptance using FAHP and TOPSIS methods: A case study of Iranian vehicle belt production industry, International Journal of Industrial Engineering Computations 3: 211-224. http://dx.doi.org/10.5267/j.ijiec.2011.08.002

Pavri, Z. 1999. Valuation of intellectual property assets: the foundation for risk management and financing, in Proceedings of INSIGHT Conference, 27-29 October, 1999, Toronto.

Peldschus, F. 2009. The analysis of the quality of the results obtained with the methods of multi-criteria decisions, Technological and Economic Development of Economy 15(4): 580-592.

http://dx.doi.org/10.3846/1392-8619.2009.15.580-592 
Poh, K. L.; Ang, B. W.; Bai, F. 2001. A comparative analysis of R\&D project evaluation methods, $R \& D$ Manage 31: 63-75. http://dx.doi.org/10.1111/1467-9310.00197

President's Council of Advisors on Science and Technology (PCAST). 2005. The national nanotechnology initiative at five years: assessment and recommendations of the national nanotechnology advisory panel. Washington, USA.

Smith, G. V.; Parr, R. L. 1994. Valuation of intellectual property and intangible assets, $2^{\text {nd }}$ ed. New York: John Wiley \& Son.

Teng, J. Y.; Tzeng, G. H. 1996. Fuzzy multicriteria ranking of urban transportation investment alternative, Transportation Planning and Technology 20: 15-31. http://dx.doi.org/10.1080/03081069608717577

Verdu, A. J.; Tamayo, I.; Ruiz-Moreno, A. 2012. The moderating effect of environmental uncertainty on the relationship between real options and technological innovation in high-tech firms, Technovation 32(9-10): 579-590. http://dx.doi.org/10.1016/j.technovation.2012.06.001

Wartburg, I. V.; Teichert, T. 2008. Valuing patents and licenses from a business strategy perspective extending valuation considerations using the case of nanotechnology, World Patent Information 30: 106-114. http://dx.doi.org/10.1016/j.wpi.2007.05.007

Williams, E. 2003. Forecasting material and economic flows in the global production chain for silicon, Technological Forecasting and Social Change 70: 341-357. http://dx.doi.org/10.1016/S0040-1625(02)00201-9

Wörner, S. D.; Grupp, H. 2003. The derivation of R\&D return indicators within a real options framework, $R \& D$ Management 33: 313-325. http://dx.doi.org/10.1111/1467-9310.00300

Wu, M. C.; Yen, S. H. 2007. Pricing real growth options when the underlying assets have jump diffusion processes: the case of R\&D investments, $R \& D$ Management 37: 269-276.

Zadeh, L. A. 1965. Fuzzy sets, Information and Control 8: 338-353.

Zavadskas, E. K.; Turskis, Z. 2011. Multiple criteria decision making (MCDM) methods in economics: an overview, Technological and Economic Development of Economy 17(2): 397-427. http://dx.doi.org/10.3846/20294913.2011.593291

Zhang, X.; Liu, P. 2010. Method for aggregating triangular fuzzy intuitionistic fuzzy information and its application to decision making, Technological and Economic Development of Economy 16(2): 280-290. http://dx.doi.org/10.3846/tede.2010.18

Zhau, R.; Goving, R. 1991. Algebraic characteristics of extended fuzzy numbers, Information Science 54: 103-130. http://dx.doi.org/10.1016/0020-0255(91)90047-X

Zolfani, S. H.; Sedaghat, M.; Zavadskas, E. K. 2012. Performance evaluating of rural ICT centers (telecenters), applying fuzzy AHP, SAW-G and TOPSIS Grey, a case study in Iran, Technological and Economic Development of Economy 18(2):364-387. http://dx.doi.org/10.3846/20294913.2012.685110

An-Chin CHENG is an Assistant Professor at the Graduate Institute of Business Administration, Chaoyng University of Technology, Taiwan. He received his doctorate in Resources Engineering from National Cheng Kung University, Taiwan. He has published papers in Technovation, Technological Forecasting and Social Change, Romanian Journal of Economic Forecasting, and other journals. His current research interests include management of technology, intellectual property, and new product management. 